СРАВНИТЕЛЬНАЯ ХАРАКТЕРИСТИКА РАСПРОСТРАНЕННОСТИ ПОЛИМОРФНЫХ АЛЛЕЛЕЙ В ГЕНАХ СИСТЕМЫ ГЕМОСТАЗА (PAI-1 (-675 5G/4G) И FGB (-455 G/A)) ПРИ ВНЕЗАПНОЙ СЕРДЕЧНОЙ СМЕРТИ И ОСТРОМ КОРОНАРНОМ СИНДРОМЕ У ПАЦИЕНТОВ, ПЕРЕНЕСШИХ СТЕНТИРОВАНИЕ КОРОНАРНЫХ АРТЕРИЙ

\author{
Д.П. Березовский ${ }^{1 \star}$, И.А. Коломоец ${ }^{2}$, С.С. Бачурин ${ }^{2}$, В.Н. Егоров ${ }^{2}$, Т.В. Таютина ${ }^{2}$ \\ 1 ФГАОУ ВО «Первый Московский государственный медицинский университет им. И.М. Сеченова» Минздрава \\ России (Сеченовский Университет), Москва, Российская Федерация \\ 2 ФГБОУ ВО «Ростовский государственный медицинский университет» Минздрава России, Ростов-на-Дону, \\ Российская Федерация
}

\begin{abstract}
АННОТАЦИЯ. Цель - дать сравнительную характеристику распространенности полиморфных аллелей в генах системы гемостаза (PAI-1 (-675 5G/4G) и FGB (-455 G/A)) при внезапной сердечной смерти и остром коронарном синдроме у пациентов, перенесших стентирование коронарных артерий. Материал и методы. Выполнено генетическое типирование биологического материала (БМ) на предмет распространенности полиморбных аллелей в двух генах системы гемостаза. БМ был отобран от лич, сиагнозом ИБС, разделенных на три группы сравнения: I - внезапно умериие граждане с диагнозом ИБС, II - пациенты с ОКС, которым в ургентном порядке было выполнено стентирование коронарных артерий, III - пациенты с хронической формой ИБС, которым в плановом порядке было выполнено эндоваскулярное оперативное вмешательство. Результаты. Рассчитанный критерий $\chi^{2}$ распространенности полиморбизмов в генах FGB (-455 G/A) и PAI-1 (-675 5G/4G) оказался больше критического (табличного) значения, что свидетельствует о существующей связи между наличием ИБС и носительством одного из полиморфных аллелей. На основании тех же данных был рассчитан критерий х⿱ без учета данных по группе практически здоровых граждан. Для носителей полиморфного аллеля гена FGB (-455 G/A) статистически значимьх различий не обнаружено. Для носителей полиморфного аллеля гена PAI-1 (-675 5G/4G) статистически значимые различия обнаружены. Заключение. ОКС с благоприятным исходом (при условии экстренного оперативного вмешательства) возникает в более раннем возрасте по сравнению с внезапно умершими гражданами с диагнозом ИБС. Наличие мутантного аллеля в гене PAI-1 (-675 5G/4G) требует дальнейших исследований в иелях экспертной оценки смертельного исхода у пациентов после выполненного оперативного вмешательства со стентированием коронарных сосудов.

Ключевые слова: ишемическая болезнь серди, внезапная сердечная смерть, полиморфизм, фибриноген, ингибитор активатора плазминогена.
\end{abstract}

Для цитирования: Березовский Д.П., Коломоец И.А., Бачурин С. С., Егоров В.Н., Таютина Т. В. Сравнительная характеристика распространенности полиморфных аллелей в генах системы гемостаза (PAI-1 (-675 5G/4G) и FGB (-455 G/A)) при внезапной сердечной смерти и остром коронарном синдроме у пациентов, перенесших стентирование коронарных артерий. Судебная медищина. 2020;6(3):20-26. DOI: https://doi.org/10.19048/fm319.

Поступила 23.06.2020 Принята после доработки 18.08.2020 О Опубликована 04.10.2020

\title{
COMPARATIVE CHARACTERISTICS OF POLYMORPHIC ALLELE PROPAGATION IN THE HEMOSTASIS SYSTEM GENES PAI-1 (-675 5G/4G) AND FGB (-455 G/A) IN SUDDEN CARDIAC DEATH AND ACUTE CORONARY SYNDROME IN PATIENTS UNDERGOING CORONARY ARTERY STENTING
}

Dmitriy P. Berezovskiy ${ }^{1 \star}$, Irina A. Kolomoets ${ }^{2}$, Stanislav S. Bachurin ${ }^{2}$, Vladimir N. Egorov ${ }^{2}$, Tatiana V. Tayutina ${ }^{2}$

${ }^{1}$ I.M. Sechenov First Moscow State University (Sechenov University), Moscow, Russian Federation

${ }^{2}$ Rostov State Medical University, Rostov-on-Don, Russian Federation 
ABSTRACT. Aim. To give comparative characteristics of the prevalence of polymorphic alleles in the genes of the hemostatic system PAI-1 (-675 5G/4G) and FGB (-455 G/A) in patients with sudden cardiac death and those with acute coronary syndrome undergoing coronary artery stenting. Material and methods. Genetic typing of biological material (BM) was performed for the prevalence of polymorphic alleles in two genes of the hemostasis system. BM was selected from people with a diagnosis of coronary artery disease, divided into three comparison groups: I-suddenly deceased citizens with a diagnosis of coronary artery disease, II-patients with ACS who underwent urgent coronary artery stenting, and III-patients with a chronic form of coronary artery disease in whom endovascular surgery was performed as planned. Results. The calculated criterion $\chi^{2}$ of the prevalence of polymorphisms in the FGB (-455 G/A) and PAI-1 (-675 5G/4G) genes turned out to be more than the critical (tabular) value, which indicates an existing relationship between the presence of IHD and the carriage of one of the polymorphic alleles. Based on the same data, the $\chi^{2}$ criterion was calculated without taking into account data for a group of healthy citizens. For carriers of the polymorphic allele of the FGB gene (-455 G/A), no statistically significant differences were found. For carriers of the PAI-1 gene polymorphic allele (-675 5G/4G), statistically significant differences were found. Conclusions. ACS with a favorable outcome (subject to emergency surgical intervention) occurs at an earlier age than in patients diagnosed with coronary artery disease who die suddenly. The presence of a mutant allele in the PAI-1 gene (-675 5G/4G) requires further studies in order to expertly assess the death rate in patients after surgery with coronary stenting.

Keywords: coronary heart disease, sudden cardiac death, polymorphism, fibrinogen, plasminogen activator inhibitor.

For citation: Berezovskiy D.P., Kolomoets I.A., Bachurin S.S., Egorov V.N., Tayutina T.V. Comparative Characteristics of Polymorphic Allele Propagation in the Hemostasis System Genes PAI-1 (-675 5G/4G) and FGB (-455 G/A) in Sudden Cardiac Death and Acute Coronary Syndrome in Patients Undergoing Coronary Artery Stenting. Russian Journal of Forensic Medicine. 2020;6(3):20-26. DOI: https://doi.org/10.19048/fm319.

Submitted 23.06.2020 Revised 18.08.2020 Published 04.10.2020

\section{ВВЕДЕНИЕ}

Диагностика, лечение и профилактика сердечнососудистых заболеваний (СС3) по-прежнему остаются важнейшей проблемой в отечественной медицине. Наиболее часто врачи сталкиваются с ишемической болезнью сердца (ИБС). ИБС представляет собой острую или хроническую дисфункцию, возникающую в результате абсолютного или относительного уменьшения снабжения миокарда артериальной кровью $[1,2]$. Независимо от формы течения, ИБС может сопровождаться развитием фатальных осложнений, приводящих к внезапной сердечной смерти (ВСС). В свою очередь ВСС является объектом пристального изучения судебно-медицинскими экспертами, т. к. зачастую смерть наступает в условиях неочевидности, подозрительных на насильственную смерть.

Факторы риска развития ИБС, ВСС принято разделять на основные и дополнительные [3], наследственные и приобретенные [4].

Острая окклюзия коронарных артерий, провоцирующая развитие ОКС, может быть обусловлена тромбообразованием, в том числе и по причине нарушений в системе гемостаза. Одним из эффективных хирургических методов лечения ОКС в настоящее время считается эндоваскулярное оперативное вмешательство в виде стентирования артериальных сосудов сердца $[5,6]$. Тем не менее, как оценивать наличие наследственных факторов предрасположенности к повышенному тромбообразованию в случае летальных исходов после проведенного эндоваскулярного вмешательства по поводу развившегося ОКС, для судебно-медицинского эксперта остается не ясным. В связи с этим цель исследования - дать сравнительную характеристику распространенности полиморфных аллелей в генах системы гемостаза (PAI-1 (-675 5G/4G), FGB (-455 G/A)) при внезапной сердечной смерти и остром коронарном синдроме у пациентов, перенесших стентирование коронарных артерий.

\section{МАТЕРИАЛ И МЕТОДЫ}

Изучены данные трех медицинских организаций:

1) танатологического отдела Бюро судебно-медицинской экспертизы Ростовской области (I группа сравнения);

2) кардиохирургического отделения больницы скорой медицинской помощи (БСМП) г. Ростова-на-Дону (II группа сравнения);

3) кардиохирургического отделения клиники Ростовского государственного медицинского университета (ФГБОУ ВО РостГМУ МЗ РФ) (III группа сравнения). В I группу сравнения вошли случаи ВСС, обусловленной ИБС $(n=237)$.

II группа сравнения была представлена случаями ОКС у пациентов, находившихся на лечении в больнице скорой медицинской помощи $(n=100)$. Всем пациентам II группы сравнения было выполнено стентирование сегмента коронарных артерий в экстренном порядке.

III группа сравнения была представлена случаями ИБС у пациентов, находившихся на плановом лечении в кардиохирургическом отделении клиники РостГМУ $(n=100)$. Всем пациентам III группы сравнения в плано- 
вом порядке было выполнено стентирование сегмента коронарных артерий.

При изучении архивного материала производился учет половозрастных характеристик в отобранных группах.

В каждой из групп был осуществлен отбор биологического материала (кровь или буккальный эпителий) с целью проведения генетического типирования на предмет наличия мутаций и полиморфизмов в генах, кодирующих белки системы гемостаза. Забор биологического материала осуществлялся с добровольного согласия обследуемых, либо из архива Бюро судебно-медицинской экспертизы Ростовской области. Количество выполненных генетических исследований в каждой из анализируемых групп указано в табл. 1.

Идентификацию однонуклеотидных полиморфизмов (ОНП) генов FGB (-455 G/A), PAI-1 (-675 5G/4G) проводили методом энзиматической амплификации в реальном времени с помощью наборов реагентов серии «SNP-Скрин» (Синтол, Россия, Москва) с использованием компьютеризированного четырехканального устройства «АНК-32». Характеристика исследованных генов и их аллельных вариантов представлены в табл. 2.

Полученные количественные результаты подвергались обработке методом вариационной статистики в программе Microsoft Excel 2016 с определением среднего значения, ошибки среднего, 25-го и 75-го процентиля, медианы, минимального и максимального значений.

\section{РЕЗУЛЬТАТЫ}

В I группе сравнения среднее значение возраста составило 71,34 \pm 0,72 года (минимальное значение 35 лет, медиана 73 года, максимальное значение 92 года,
25\% процентиль 64 года, 75\% процентиль 79 лет). Дополнительно проведенное генетическое типирование на предмет распространенности полиморфных аллелей в генах PAI-1 (-675 5G/4G) и FGB (-455 G/A) выявило следующие особенности: носителями дикого генотипа в гене PAI-1 (-675 5G/4G) были 6 умерших (20\%), гомозиготные и гетерозиготные мутантные аллели обнаружены в равном числе случаев - по 12 (40\%). Носительство аллельных вариантов в гене FGB (-455 G/A) в данной группе сравнения было представлено следующим образом: с диким вариантом выявлено 70\% случаев $(n=21)$, с гетерозиготным - 30\% $(n=9)$.

Bo II группе сравнения средний возраст пациентов составил 60,06 \pm 0,96 года (минимальное значение 36 лет, максимальное значение 79 лет, медиана 60 лет, 25\% процентиль 53 года, 75\% процентиль 68 лет).

Дополнительно проведенное генетическое типирование на предмет распространенности полиморфных аллелей в генах PAI-1 (-675 5G/4G) и FGB (-455 G/A) выявило следующие особенности: носителей дикого генотипа в гене PAI-1 (5G/5G) было 4 (4,2\%), с гомозиготным мутантным аллелем - 60 случаев $(63,2 \%)$ и в гетерозиготном состоянии с мутантным аллелем - 31 (32,6\%). Носителей гена FGB (-455 G/A) в диком аллельном состоянии было 56 (58,9\%), в гетерозиготном - 30 (31,6\%), в гомозиготном $A / A-9(9,5 \%)$.

B III группе сравнения средний возраст пациентов составил 64,89 \pm 0,9 года (минимальное значение 43 года, максимальное значение 88 лет, медиана 66,5 лет, 25\% процентиль 58 лет, 75\% процентиль 70 лет). Носителей дикого генотипа в гене PAI-1 (-675 5G/4G) было 9 (9,47\%), гомозиготных по мутантному аллелю $(4 G / 4 G)-57$ случаев $(60 \%)$ и в гетерозиготном состоянии - 29 случаев (30,53\%). Носителей дикого аллелея $G / G$ в гене $F G B(-455$ G/A)

Таблица 1. Количество отобранных биологических образцов в группах сравнения

Table 1. The number of selected biological samples in comparison groups

\begin{tabular}{|l|c|c|}
\hline \multicolumn{1}{|c|}{ Группа сравнения } & $\begin{array}{c}\text { Количество отобранных образцов } \\
\text { для генетического типирования }\end{array}$ & $\begin{array}{c}\text { Обще количество } \\
\text { в выборке }\end{array}$ \\
\hline I группа сравнения & 30 & 100 \\
\hline II группа сравнения & 95 & 100 \\
\hline III группа сравнения & 95 & \\
\hline
\end{tabular}

Таблица 2. Характеристика исследованных генов и их аллельных вариантов

Table 2. Characteristics of the studied genes and their allelic variants

\begin{tabular}{|l|l|c|}
\hline \multicolumn{1}{|c|}{ Ген, локализация } & \multicolumn{1}{|c|}{ Название белкового продукта гена } & \multicolumn{2}{|c|}{ Полиморфизм } \\
\hline FGB $4 q 28$ & Фибриноген & rs 1800790 \\
\hline$P A I-17 q 21.3-q 22$ & Ингибитор активации плазминогена & $-455 / A$ \\
\hline
\end{tabular}


среди анализируемых случаев было 67 (70,53\%), с мутантным аллелем в гетерозиготном состоянии $28(29,47 \%)$, носителей с мутантным аллелем в гомозиготном состоянии не выявлено.

Сводные данные о количестве носителей однонуклеотидных полиморфных аллелей в исследуемых генах приведены в табл. 3.

Связь между распространенностью полиморфных аллелей в генах PAI-1 (-675 5G/4G) и FGB (-455 G/A) и наличием ИБС оценивалась с помощью расчета критерия $\chi^{2}$. Так как в I, III группах и группе практически здоровых граждан не было выявлено носителей гомозиготного мутантного аллельного варианта в гене FGB (-455 G/A), то этот вариант не учитывался при дальнейшем статистическом анализе. Количество носителей соответствующего полиморфного аллеля в каждой группе сравнения было сведено в табл. 4.
В обоих случаях рассчитанный критерий $\chi^{2}$ оказался больше критического (табличного) значения: для FGB (-455 G/A) - 140,44, для PAI-1 (-675 5G/4G) 39,24 ; критические значения критерия при уровне значимости 0,01 составили 11,345 и 16,81 соответственно, что свидетельствует о существующей связи между наличием ИБС и носительством одного из полиморфных аллелей в генах $F G B(-455 G / A)$ или PAI-1 (-675 5G/4G).

На основании тех же данных был рассчитан критерий $\chi^{2}$ без учета данных по группе практически здоровых граждан. Для носителей полиморфного аллеля гена FGB (-455 G/A) статистически значимых различий не обнаружено $\left(\chi^{2}=0,659\right.$ при критическом значении $\left.\chi^{2}=5,991\right)$. Для носителей полиморфного аллеля гена PAI-1 (-675 5G/4G) значение $\chi^{2}$ составило 9,481 при уровне значимости $p=0,051$ (критическое значение $\chi^{2}$ составляет 9,440). Гетеро- и гомозиготный

Таблица 3. Распределение носителей с полиморфными аллелями в генах системы гемостаза в зависимости от группы сравнения

Table 3. Carrier distribution with polymorphic alleles in the hemostatic system genes, depending on the comparison group

\begin{tabular}{|l|l|c|c|c|}
\hline \multicolumn{1}{|c|}{ Группы сравнения } & \multicolumn{1}{|c|}{ Ген } & $\begin{array}{c}\text { Дикий тип } \\
\text { генотипа (-/-) } \\
\text { (в \%) }\end{array}$ & $\begin{array}{c}\text { Гетерозиготный } \\
\text { вариант (+/-) } \\
\text { (в \%) }\end{array}$ & $\begin{array}{c}\text { Гомозиготный вариант } \\
\text { по полиморфному } \\
\text { аллелю (+/+) (в \%) }\end{array}$ \\
\hline \multirow{2}{*}{ I } & PAI-1-675 5G/4G & 20 & 40 & 40 \\
\cline { 2 - 5 } & $F G B-455 G / A$ & 70 & 30 & 0 \\
\hline \multirow{2}{*}{ II } & PAI-1-675 5G/4G & 4,2 & 32,6 & 63,2 \\
\hline \multirow{2}{*}{ III } & $F G B-455 G / A$ & 58,9 & 31,6 & 9,5 \\
\hline \multirow{2}{*}{$\begin{array}{l}\text { Практически здоровые граждане } \\
\text { (Ростовская область) [7] }\end{array}$} & PAI-1-675 5G/4G & 9,47 & 30,53 & 60 \\
\cline { 2 - 5 } & $F G B-455 G / A$ & 70,53 & 29,47 & 0 \\
\hline
\end{tabular}

Таблица 4. Распределение носителей с полиморфными аллелями в генах системы гемостаза в зависимости от группы сравнения для расчета критерия $\chi^{2}$

Table 4. Carrier distribution with polymorphic alleles in the hemostatic system genes, depending on the comparison group to calculate the $\chi^{2}$ test

\begin{tabular}{|c|c|c|c|c|c|}
\hline Группы сравнения & I группа & II группа & III группа & Практ. здоровые & Всего \\
\hline Полиморфизм & \multicolumn{5}{|c|}{$F G B-455 G / A$} \\
\hline Дикий тип генотипа (-/-) (N) & 21 & 56 & 67 & 97 & 241 \\
\hline Гетерозиготный вариант (+/-) (N) & 9 & 30 & 28 & 3 & 70 \\
\hline Всего & 30 & 86 & 95 & 100 & 311 \\
\hline Полиморфизм & \multicolumn{5}{|c|}{$P A I-1-6755 G / 4 G$} \\
\hline Дикий тип генотипа (-/-) (N) & 6 & 4 & 9 & 27 & 46 \\
\hline Гетерозиготный вариант (+/-) (N) & 12 & 31 & 29 & 53 & 125 \\
\hline $\begin{array}{l}\text { Гомозиготный вариант } \\
\text { по полиморфному аллелю (+/+) (N) }\end{array}$ & 12 & 60 & 57 & 20 & 149 \\
\hline Всего & 30 & 95 & 95 & 100 & 320 \\
\hline
\end{tabular}


варианты по полиморфному аллелю преобладали у пациентов с хроническим и острым течением ИБС (II и III группы сравнения). Дикий генотип имел одинаковое распространение среди всех трех сравниваемых групп.

\section{ОБСУЖДЕНИЕ}

Анализ современной литературы позволяет утверждать, что проблема внезапной сердечной смерти попрежнему остается актуальной [8]. Бесспорным признается утверждение, что причиной внезапной смерти в большинстве случаев является ИБС, атеросклероз венечных (коронарных) артерий и, как следствие, развитие ОКС.

Проведенное нами исследование установило статистически значимое различие в среднем возрасте при попарном сравнении каждой из трех групп. Максимальное значение возраста было зафиксировано в группе внезапно умерших граждан, минимальное в группе ОКС.

Современная стратегия лечения пациентов с ИБС, осложненной развитием ОКС, сводится к применению интервенционного хирургического метода - стентирования венечных (коронарных) артерий $[5,6]$. В патогенезе развития ОКС ведущая роль отведена окклюзии коронарной артерии вследствие тромбообразования на поверхности изъязвленной атеросклеротической бляшки. Скорость тромбообразования, а в последующем и его лизис зависят от многих факторов, в том числе и от наследственных, обусловленных наличием полиморфных аллелей в генах, кодирующих белки системы гемостаза. Нет сомнений, что многие пациенты с СС3 имеют наследственную предрасположенность к их развитию [9]. Однако, по мнению цитируемых авторов, «данные, сообщающие о частоте встречаемости полиморфизмов системы гемостаза у пациентов с ОКС, разрозненные и противоречивые». В настоящей работе была предпринята попытка оценки наследственных факторов предрасположенности к повышенному тромбообразованию с позиций судебно-медицинского эксперта при анализе случаев ВСС, в связи с чем были изучены биологические образцы от лиц, страдающих или страдавших острой и/или хронической формами ИБС. Во всех анализируемых группах были изучены данные о распространенности полиморфных аллей в генах, кодирующих всего два белка системы гемостаза, - ингибитора активации плазминогена PAI-1 (-675 5G/4G) и фибриногена FGB (-455 G/A).

Сравнение полученных результатов о количестве носителей полиморфных аллелей было произведено с ранее полученными нами результатами от лиц, признанных практически здоровыми [7] (см. табл. 3).

Установлено, что в группе лиц с ОКС, прооперированных в экстренном порядке (II группа), было вы- явлено увеличение количества носителей мутантного аллеля в гомозиготном состоянии в гене FGB (-455 G/A) по сравнению с группами лиц, которым в плановом порядке было выполнено стентирование коронарных артерий (III группа) или внезапно умерших (I группа). Однако анализ критерия $\chi^{2}$ не установил статистически значимых различий.

Фибриноген (FGB beta polypeptide, фактор I) является белком острой фазы воспаления [10]. По данным литературы, вариант G-455A в гене $\beta$-субъединицы фибриногена (FGB) обусловливает повышенную транскрипцию гена и, соответственно, приводит к повышенному уровню фибриногена в крови, что влечет за собой увеличение вероятности образования тромбов [11]. Тем не менее необходимо отметить, что в группе внезапно умерших граждан носителей мутантного аллеля в гомозиготном состоянии не установлено. Данный факт свидетельствует в пользу того, что ведущим в патогенезе ВСС является нарушение сердечного ритма. Этим и объясняется относительно редкие находки тромбов в коронарных артериях у внезапно умерших граждан, тела которых были подвергнуты судебно-медицинскому исследованию с постановкой диагноза ИБС.

Полученные данные в отношении количества носителей мутантного аллеля в гене PAI-1 (-675 5G/4G) позволило установить высокий процент носителей как в гомозиготном, так и гетерозиготном состоянии во всех исследуемых группах. По данным литературы, PAI-1 (ингибитор активатора плазминогена SERPINE1, PAI-I) является одним из основных компонентов тромболитической плазминоген-плазминовой системы [12]. Вариант $4 G$ приводит к повышенной экспрессии гена и, соответственно, к повышенному уровню PAI-1 в крови. Следовательно, тромболитическая система менее эффективна, и скорость лизиса вновь образованного тромба, а тем самым и реканализация тромбированного сосуда замедляются. Вариант $4 G / 4 G$ ассоциирован с наличием семейного анамнеза ИБС [13].

\section{ЗАКЛЮЧЕНИЕ}

Таким образом, полученные данные свидетельствуют о том, что ОКС с благоприятным исходом (при условии экстренного оперативного вмешательства) возникает в более раннем возрасте по сравнению с внезапно умершими гражданами с диагнозом ИБС.

Для всех групп сравнения с диагнозом ИБС характерно преобладание мутантных аллелей в генах системы гемостаза по сравнению с контрольной группой практически здоровых граждан.

Статистически значимые различия между группами сравнения с диагнозом ИБС установлены лишь для носителей мутантных аллелей в гене PAI-1.

Наличие мутантного аллеля в гене PAI-1 требует дальнейших исследований в целях экспертной оценки 
смертельного исхода у пациентов после выполненного оперативного вмешательства со стентированием коронарных сосудов.

\section{ВКЛАД АВТОРОВ}

Все авторы внесли существенный вклад в разработку концепции, проведение исследования и подготовку статьи, прочли и одобрили финальную версию перед публикацией.

\section{AUTHOR CONTRIBUTION}

Authors are solely responsible for submitting the final manuscript to print. All authors participated in the development of the concept of the article and the writing of the manuscript. The final version of the manuscript

\section{ЛИТЕРАТУРА • REFERENCES}

1. Бокерия Л.А., Гудкова Р.Г. Сердечно-сосудистая хирургия-2010. Болезни и врожденные аномалии системь кровообращения. М.: НЦССХ им. А.Н. Бакулева РАМН, 2011. 192 c. [Bokeria L.A., Gudkova R.G. Serdechno-sosudistaya khirurgiya-2010. Serdechno-sosudistaya khirurgiya-2010. Bolezni $i$ vrozhdennyye anomalii sistemy krovoobrashcheniya. Moscow: Bakulev's SCCVS RAMS, 2011. 192 p. (In Russ.)]

2. Бокерия Л.А., Пирцхалаишвили З.К., Сигаев И.Ж., и др. Современные подходы к диагностике и хирургическому лечению брахиоцефальных артерий у больных ишемической болезнью сердца. Вестник Российской академии медицинских наук. 2012;67(10):4-11. [Bokeria L.A., Pirtskhalaishvili Z.K., Sigaev I.J., et al. Modern approaches to the diagnosis and surgical treatment of brachiocephalic arteries in patients with coronary heart disease. Annals of the Russian Academy of Medical Sciences. 2012;67(10):4-11. (In Russ.)]. https://doi.org/10.15690/vramn.v67i10.410

3. Malakar A.K., Choudhury D., Halder B., et al. A review on coronary artery disease, its risk factors, and therapeutics. J Cell Physiol. 2019;234(10):16812-16823. https://doi.org/10.1002/jcp.28350

4. Fishman G.I., Chugh S.S., di Marco J.P., et al. Sudden cardiac death prediction and prevention: report from a national heart, lung, and blood institute and heart rhythm society workshop. Circulation. 2010;122(22):2335-2348. https://doi.org/10.1161/circulationaha.110.976092

5. Raggi P. [Coronary artery calcium: pathogenesis and cardiovascular risk. (In Italian)]. Giornale Italiano di Cardiologia (Rome). 2019;20(7):401-408. https://doi.org/10.1714/3190.31683

6. Moreyra E. Jr., Lorenzatti D., Moreyra C., et al. [Comparison of risk scores to predict subclinical atherosclerosis. (In Spanish)]. Medicina (B Aires). 2019;79(5):373-383.

7. Березовский Д.П., Варавва Т.А., Фалеева Т.Г., и др. Судебно-медицинская оценка наследственной предрасположенности к тромбофилии в случаях тромботических осложнений механической травмы. Судебно-медицинская was approved by all authors. The authors are grateful to anonymous reviewers for helpful comments.

\section{ИСТОЧНИК ФИНАНСИРОВАНИЯ}

Исследование не имело спонсорской поддержки.

\section{FUNDING SOURCE}

The study had no sponsorship.

\section{КОНФЛИКТ ИНТЕРЕСОВ}

Конфликт интересов отсутствует.

\section{COMPETING INTERESTS}

The authors declare no apparent or potential conflicts of interest. экспертиза. 2014;57(1):22-25. [Berezovskii D.P., Varavva T.A., Faleeva T.G., et al. Forensic medical evaluation of hereditary predisposition to thrombophilia in the case of thrombotic complications of a mechanical injury. Russian journal of forensic medicine. 2014;57(1):22-25. (In Russ.)]

8. Chen C.F., Jin C.L., Liu M.J., Xu Y.Z. Efficacy, safety, and inhospital outcomes of subcutaneous versus transvenous implantable defibrillator therapy: A meta-analysis and systematic review. Medicine (Baltimore). 2019;98(19):e15490. https:// doi.org/10.1097/MD.0000000000015490

9. Воронова И.Л., Шавкунов С.А., Павлова Т.В., и др. Анализ распространенности генных полиморфизмов системы гемостаза у пациентов с острым коронарным синдромом. В кн.: Молекулярная диагностика-2017. Т. 2. М., 2017. C. 124-125. [Voronova I.L., Shavkunov S.A., Pavlova T.V., et al. Analysis of the prevalence of gene polymorphisms of the hemostasis system in patients with acute coronary syndrome. In: Molecular diagnosis-2017. Vol. 2. Moscow; 2017. P. 124-125. (In Russ.)]

10. Refaai M.A., Riley P., Mardovina T., Bell P.D. The clinical significance of fibrin monomers. Thromb Haemost. 2018;118(11): 1856-1866. https://doi.org/10.1055/s-0038-1673684

11. Shah S.A., Kondkar A.A., Ashavaid T.F. An in-house multilocus SNP genotyping assay for evaluation of complex genetic diseases. Scand J Clin Lab Invest. 2016;76(7):590-595. https:// doi.org/10.1080/00365513.2016.1218535

12. Akhter M.S., Biswas A., Abdullah S.M., et al. The role of PAI-1 4G/5G promoter polymorphism and its levels in the development of ischemic stroke in young Indian population. Clin Appl Thromb Hemost. 2017;23(8):1071-1076. https:// doi.org/10.1177/1076029617705728

13. Margaglione M., Brancaccio V., Giuliani N., et al. Increased risk for venous thrombosis in carriers of the prothrombin $\mathrm{G} \rightarrow \mathrm{A} 20210$ gene variant. Ann Intern Med. 1998;129(2):89-93. https://doi.org/10.7326/0003-4819-129-2-199807150-00003 


\section{OБ ABTOPAX • AUTHORS}

* БЕРЕЗОВСКИЙ Дмитрий Павлович - д.м.Н., доц., профессор кафедры судебной медицины Первого Московского государственного университета им. И.М. Сеченова • dpb@mail.ru • SPIN-код: 4063-5837, AuthorID: 634134; ORCID: https://orcid.org/0000-0002-8502-1331

КОЛОМОЕЦ Ирина Анатольевна - ассистент кафедры судебной медицины Ростовского государственного медицинского университета Минздрава России • ira.kolomoets.73@mail.ru • SPIN-код: 5514-9370; AuthorID: 832351; ORCID: https://orcid.org/0000-0001-7736-1400

БАЧУРИН Станислав Сергеевич - к.Х.н., старший преподаватель кафедры общей и клинической биохимии № 2 Ростовского государственного медицинского университета Минздрава России • bachurin_ss@rostgmu.ru•SPIN-код: 3150-6795, AuthorID: 780600, ORCID: https://orcid.org/0000-0002-4349-5897

ЕГОРОВ Владимир Николаевич - к.м.н., доц., доцент кафедры поликлинической терапии Ростовского государственного медицинского университета Минздрава России • suslik78@mail.ru •SPIN-код: 6911-1023, AuthorID: 645942; ORCID: https://orcid.org/0000-0002-0661-9985

ТАЮТИНА Татьяна Владимировна - к.м.н., доц., доцент кафедры поликлинической терапии Ростовского государственного медицинского университета Минздрава России • tarus76@mail.ru • SPIN-код: 7371-6260, AuthorID: 635604; ORCID: https://orcid.org/0000-0002-5421-4202
Dmitriy P. Berezovskiy - Doc. Sci. (Med.), Ass. prof., I. M. Sechenov First Moscow State University • dpb@mail.ru • SPIN-код: 4063-5837, AuthorID: 634134; ORCID: https://orcid.org/0000-0002-8502-1331

Irina A. Kolomoets - Assistant, Rostov State Medical University • ira.kolomoets.73@mail.ru • SPIN-код: 5514-9370; AuthorID: 832351; ORCID: https://orcid.org/0000-0001-7736-1400

Stanislav S. Bachurin - Cand. Sci. (Chem.), Rostov State Medical University • bachurin_ss@rostgmu.ru • SPIN-код: 3150-6795, AuthorID: 780600, ORCID: https://orcid.org/0000-0002-4349-5897

Vladimir N. Egorov - Cand. Sci. (Med.), Ass. Prof., Rostov State Medical University • suslik78@mail.ru • SPIN-код: 6911-1023, AuthorID: 645942; ORCID: https://orcid.org/0000-0002-0661-9985

Tatiana V. Tayutina - Cand. Sci. (Med.), Ass. Prof., Rostov State Medical University • tarus76@mail.ru • SPIN-код: 7371-6260, AuthorID: 635604; ORCID: https://orcid.org/0000-0002-5421-4202 